\title{
Finite Element Modeling of Compressive and Splitting Tensile Behavior of Plain Concrete and Steel Fiber Reinforced Concrete Cylinder Specimens
}

\author{
Md. Arman Chowdhury, Md. Mashfiqul Islam, and Zubayer Ibna Zahid \\ Ahsanullah University of Science and Technology, Dhaka 1208, Bangladesh \\ Correspondence should be addressed to Md. Arman Chowdhury; arman.chowdhury.ce@gmail.com
}

Received 17 November 2015; Accepted 21 February 2016

Academic Editor: Hossein Moayedi

Copyright (C) 2016 Md. Arman Chowdhury et al. This is an open access article distributed under the Creative Commons Attribution License, which permits unrestricted use, distribution, and reproduction in any medium, provided the original work is properly cited.

Plain concrete and steel fiber reinforced concrete (SFRC) cylinder specimens are modeled in the finite element (FE) platform of ANSYS 10.0 and validated with the experimental results and failure patterns. Experimental investigations are conducted to study the increase in compressive and tensile capacity of cylindrical specimens made of stone and brick concrete and SFRC. Satisfactory compressive and tensile capacity improvement is observed by adding steel fibers of $1.5 \%$ volumetric ratio. A total of 8 numbers of cylinder specimens are cast and tested in $1000 \mathrm{kN}$ capacity digital universal testing machine (UTM) and also modeled in ANSYS. The enhancement of compressive strength and splitting tensile strength of SFRC specimen is achieved up to $17 \%$ and $146 \%$, respectively, compared to respective plain concrete specimen. Results gathered from finite element analyses are validated with the experimental test results by identifying as well as optimizing the controlling parameters to make FE models. Modulus of elasticity, Poisson's ratio, stress-strain behavior, tensile strength, density, and shear transfer coefficients for open and closed cracks are found to be the main governing parameters for successful model of plain concrete and SFRC in FE platform. After proper evaluation and logical optimization of these parameters by extensive analyses, finite element (FE) models showed a good correlation with the experimental results.

\section{Introduction}

Steel fiber reinforced concrete (SFRC) is a cement-based material reinforced with short discrete steel fibers randomly distributed in the concrete matrix. When steel fibers are added to a concrete mix, they act as crack arrestors and prevent the propagation of cracks by bridging. Strength and ductility of structures depend mainly on proper detailing of the reinforcement in structural members. Brittle failure of these members may lead to catastrophic damage to the structure and the people living on these structures. To increase the ductility of the structural members, construction of steel fiber reinforced concrete (SFRC) can be an efficient technique.

Cylinder compressive strength is widely used as a proxy for any number of other concrete properties, in addition to its obvious role relating to the compressive strength of the structural concrete. In the history of modern structural concrete, compressive strength is one of the most important properties, if not the most important one, in terms of verifying acceptability of a wide range of concrete behaviors to a structure's performance [1]. In high seismic risk regions, to improve confinement, closely spaced hoops often result in highly congested columns that may cause problems during construction. The use of SFRC in such columns may permit a reduction in the amount of transverse reinforcement, leading to improved constructability [2].

Steel fiber is used as a volume percentage in the concrete which enhances the bond strength. Load carrying capacity of SFRC at postcracking stage made it the point of interest in modern researches. Steel fibers of high tensile capacity arrest the microcracks. In the hardened state, when fibers are properly bonded, they interact with the matrix at the level of microcracks and effectively bridge the cracks thereby providing stress transfer media that delay their coalescence and unstable growth as shown in Figure $1[3,4]$. 
Finite element analysis, as used in structural engineering, determines the overall behavior of a structure by dividing it into a number of simple elements, each of which has well-defined mechanical and physical properties. Modeling the complex behavior of reinforced concrete, which is both nonhomogeneous and anisotropic, is a difficult challenge in the finite element analysis of civil engineering structures. A reasonable modeling of concrete on a finite element (FE) platform can be done by using suitable element type, adequate mesh size, appropriate boundary conditions, realistic loading environment, and proper time stepping as well as providing pertinent parameters of concrete. Using these pertinent parameters (i.e., Poison's ratio, tensile strength, the stressstrain relationship, density, shear transfer coefficients, compressive strength, modulus of elasticity, etc.) all the cylindrical specimens are modeled, analyzed, and compared with the results gathered from experimental outcomes. A satisfactory and reliable agreement is found between the experimental specimens and the FE models.

Extensive mesh analysis is done to estimate the optimum number of elements to get the most accurate result in best possible time. Cylinder specimen for two different concrete types made of brick and stone is modeled in ANSYS 10.0. Loading and boundary condition are applied as tested experimentally. In compressive strength test of brick and stone concrete cylinders show nice similarities of the stress-strain pattern between the experimental output and ANSYS model. Tensile behavior of the brick and stone concrete in split cylinder tests and ANSYS models also showed similarities and followed almost the same path. The evaluation of the results gathered from the experimental measurements with the FE analysis by ANSYS 10.0 upholds a good agreement and satisfactorily demonstrates the accuracy of the FE model plain concrete as well as that of the SFRC. Also failure pattern found in FE analysis matches wonderfully with the experimental failure pattern, which is also an evidence of good FE modeling of plain concrete and SFRC.

The objectives of the study are to investigate the compressive and splitting tensile capacity enhancement of SFRC using brick and stone aggregates and to use customized steel fibers of low aspect ratio and low tensile strength, prepared from available engineering materials. Another important objective is to conduct FE modeling and analysis of the SFRC specimens and validate the FE outcomes with experimental results and failure patterns. Due to lack of reliable experimental results, SFRC construction has not been started yet in Bangladesh though SFRC possesses improved mechanical properties and impact resistance, controlled crack propagation, significant postpeak ductility, and energy absorption capacity [6]. These experimental results and FE outcomes will be helpful to introduce SFRC in the construction industry in Bangladesh to build resilient structures with reasonable confidence.

\section{Experimental Investigation}

2.1. Experimental Program. Two types of coarse aggregates (CA), that is, brick and stone, are used to prepare the plain
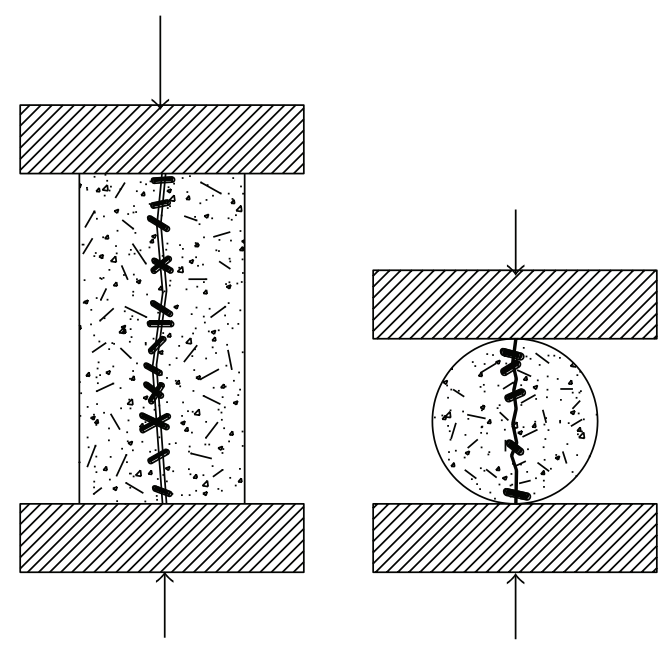

FIGURE 1: Crack bridging of SFRC by steel fibers in compression and splitting tension test of cylinder specimen.

concrete and SFRC cylindrical specimens. The sizes of the aggregates are maintained by passing it through sieve where $50 \%$ of the total aggregate is taken from those who passed 1-inch sieve and retained on $3 / 4$ inch sieve and another $50 \%$ is taken from $3 / 4$ inch passing and $1 / 2$ inch retained on sieve. Sylhet sand is taken as fine aggregate (FA). The water cement ratio $(\mathrm{w} / \mathrm{c})$ is maintained at 0.45 and the ratio of cement:FA: $\mathrm{CA}$ used is $1: 1.5: 3$. The compressive and tensile (splitting) strength are measured according to ASTM C 39/C 39M-05 [7] and ASTM C 496/C 496M-04 [8], respectively, by the concrete cylinder specimens of 4 in $(100 \mathrm{~mm})$ diameter and 8 in $(200 \mathrm{~mm})$ height. Strain data are measured by applying digital image correlation technique (DICT) using high definition (HD) images and high speed video clips and these data are synthesized with the load data from the load cell of UTM (see also [9-11]). A total of 8 concrete cylinders are cast, tested, and modeled in ANSYS to predict the compressive and tensile capacity enhancements. According to ACI-544.4R-88 [5] (Figure 2), enlarged-end fibers show the maximum energy absorption as well as tensile capacity, which is the reason for utilizing enlarged-end fibers in this research to make the SFRC. These fibers, prepared in the laboratory, are made of modified cold drawn wire (ASTM A 820/A 820M-06 [12] Type V) and consist of tensile strength 80,000 psi that satisfies ASTM A 820/A 820M-06 [12] (minimum tensile strength should be 50,000 psi). The geometry and image of fibers are shown in Figure 3.

2.2. Engineering Properties of Concrete. The average compressive strength of brick and stone plain concrete is $3500 \mathrm{psi}$ $(24.5 \mathrm{MPa})$ and $4100 \mathrm{psi}(28.7 \mathrm{MPa})$, respectively, while tensile strength is $648 \mathrm{psi}(4.5 \mathrm{MPa})$ and $448 \mathrm{psi}$ ( $3 \mathrm{MPa})$, respectively. Besides, the average compressive strength of brick and stone SFRC (1.5\% steel fiber volume) is $4100 \mathrm{psi}(28.7 \mathrm{MPa})$ and $4800 \mathrm{psi}(33.6 \mathrm{MPa})$, respectively, and tensile strength is $944 \mathrm{psi}(6.5 \mathrm{MPa})$ and $1104 \mathrm{psi}(7.6 \mathrm{MPa})$, respectively. These results are provided in Table 1. 

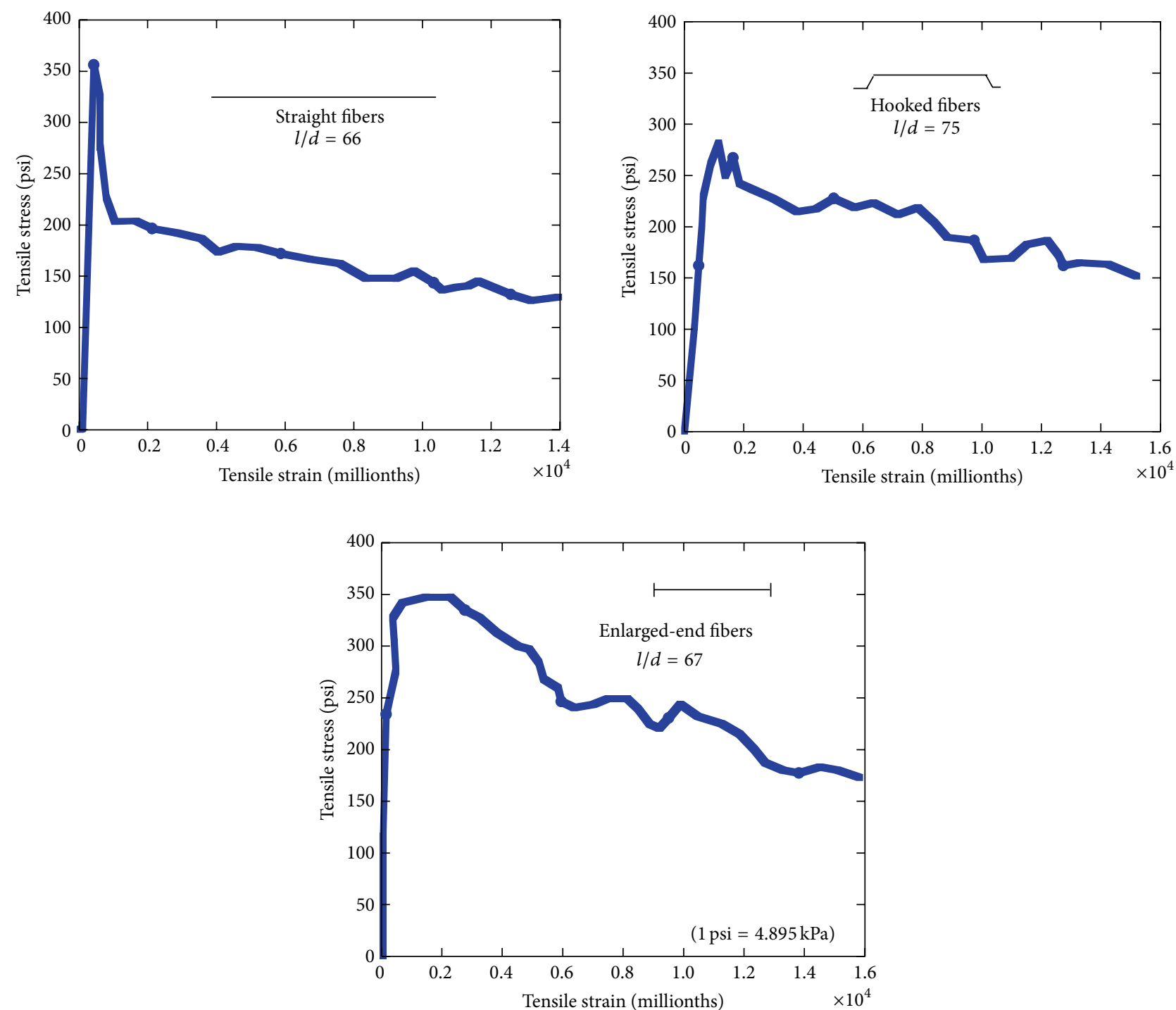

FIGURE 2: Stress-strain curves for steel fiber reinforced mortars in tension as per ACI-544.4R-88 [5].

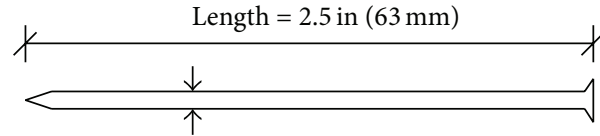

Dia, $d=0.082$ in $(2.1 \mathrm{~mm})$

Length, $l=1.75$ in $(44.5 \mathrm{~mm})$

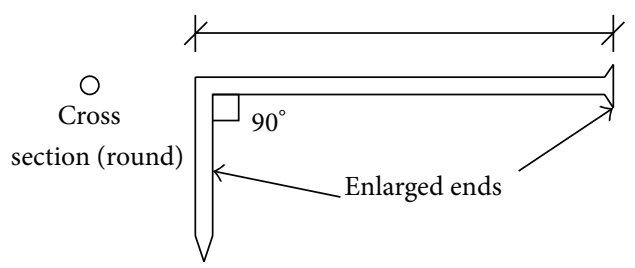

(a)

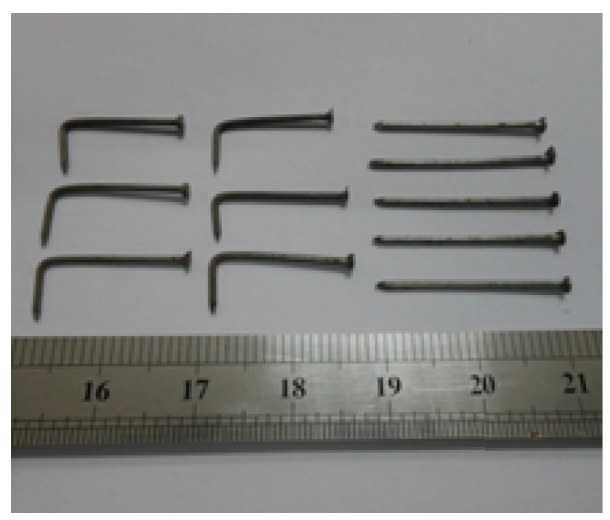

(b)

FiguRE 3: ((a) and (b)) Size and geometry of the customized enlarged ends steel fibers employed in this research. 

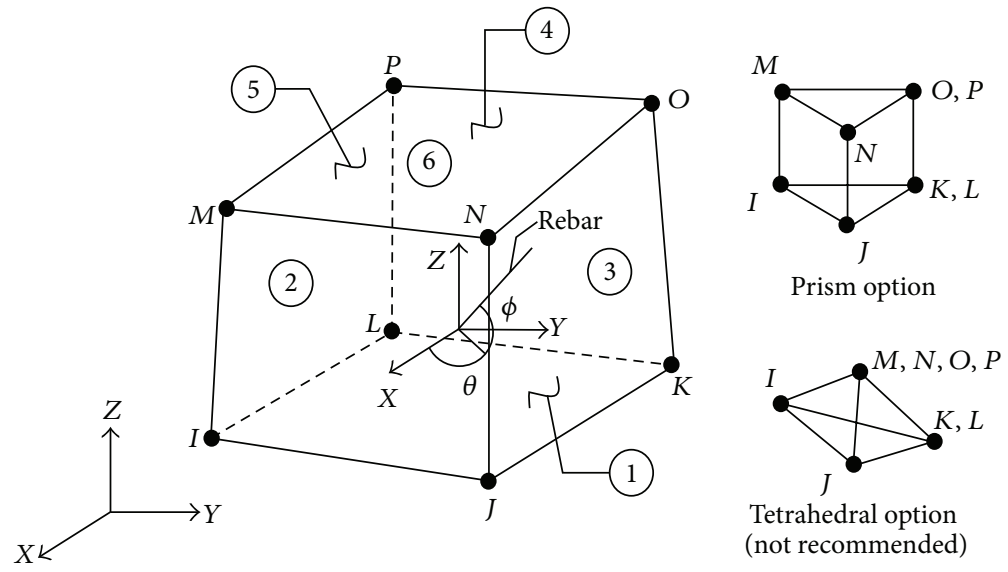

FIGURE 4: Geometry of SOLID65 in ANSYS 10.0 platform.

TABLE 1: Engineering properties of concrete.

\begin{tabular}{lccc}
\hline $\begin{array}{l}\text { Type of } \\
\text { concrete }\end{array}$ & $\begin{array}{c}\text { Steel fiber } \\
\text { volume (\%) }\end{array}$ & $\begin{array}{c}\text { Compressive } \\
\text { strength } \\
\text { psi (MPa) }\end{array}$ & $\begin{array}{c}\text { Tensile strength } \\
\text { psi (MPa) }\end{array}$ \\
\hline $\begin{array}{l}\text { Brick } \\
\text { concrete }\end{array}$ & 0 & $3500(24.5)$ & $648(4.5)$ \\
$\begin{array}{l}\text { Stone } \\
\text { concrete }\end{array}$ & 0 & $4100(28.7)$ & $448(3)$ \\
$\begin{array}{l}\text { Brick SFRC } \\
\text { Stone SFRC }\end{array}$ & 1.5 & $4100(28.7)$ & $944(6.5)$ \\
\hline
\end{tabular}

\section{Finite Element (FE) Modeling}

3.1. Element Type. A solid element having eight (8) nodes, SOLID65, is used to model the plain concrete and also SFRC in the ANSYS FE platform. SOLID65 is used for the 3D modeling of solids with or without reinforcing bars (rebar). The solid is capable of cracking in tension and being crushed in compression, just like concrete is. In concrete applications, for example, the solid capability of the element may be used to model the concrete while the rebar capability is available for modeling reinforcement behavior. Other cases for which the element is equally applicable would be reinforced composites such as fiberglass and in this case steel fiber reinforced concrete (SFRC). This is why individual fibers need not be modeled, while governing material properties from experimental investigation can make SFRC models perform as reinforced composites. The element (SOLID65) is defined by eight nodes having three degrees of freedom at each node: translations in the nodal $x, y$, and $z$ directions. The geometry of SOLID65 is shown in Figure 4.

3.2. FE Material Properties. To model concrete and SFRC in ANSYS platform the following properties are to be provided, that is, (i) elastic modulus, (ii) compressive stress-strain relationship, (iii) ultimate uniaxial tensile strength, and (iv) Poisson's ratio. All the values are provided from experimental outputs. Poisson's ratio for concrete and SFRC is estimated to be 0.25 and 0.35 for stone and brick concrete, respectively, by extensive numerical trials and matching experimental and FE stress-strain response. William and Warnke [13] failure criterion is applied to model the concrete as well as SFRC. Four important parameters, that is, (i) shear transfer coefficients for an open crack, (ii) shear transfer coefficients for a closed crack, (iii) uniaxial tensile cracking stress, and (iv) uniaxial crushing stress, are also considered to model the concrete and SFRC. Typical shear transfer coefficients range from 0.0 to 1.0 , with 0.0 representing a smooth crack (complete loss of shear transfer) and 1.0 representing a rough crack (no loss of shear transfer). The shear transfer coefficients for open and closed cracks are determined from the work of Kachlakev et al. [14] as a basis. Table 2 provides the values of the optimized FE governing parameters considered in this investigation.

3.3. FE Model of Cylinder Specimens. Cylinders are modeled using SOLID65 element. Besides, fine mesh is applied at the hoop direction and coarse mesh is made in the centre. Figure 5 shows typical diagrams of FE model of the concrete cylinder specimens and boundary conditions.

3.4. Loading and Boundary Conditions. Cylinder specimen for two different concrete types made of brick and stone aggregates is modeled in ANSYS 10.0. Loading and boundary condition are applied as they are tested experimentally. Loading is applied as displacement boundary condition as the experimental testing is done followed by displacement control testing procedure at a rate of $0.5 \mathrm{~mm} / \mathrm{min}$. Actual pertinent parameters, such as Poison's ratio, modulus of elasticity, tensile strength, stress-strain behaviors, and shear transfer coefficients, are estimated by optimization of FE stress-strain curves with experimental results. The compression testing cylinders are restrained at the bottom surface in $X, Y$, and $Z$ directions (on nodes) and at the top surface in $X$ and $Z$ directions. At $Y$ direction downward displacement is applied. Similar displacement boundary condition is applied for splitting cylinder specimens.

3.5. Mesh Analysis. Adequate mesh size facilitates analysis of FE models appropriately within a convenient time. Mesh 


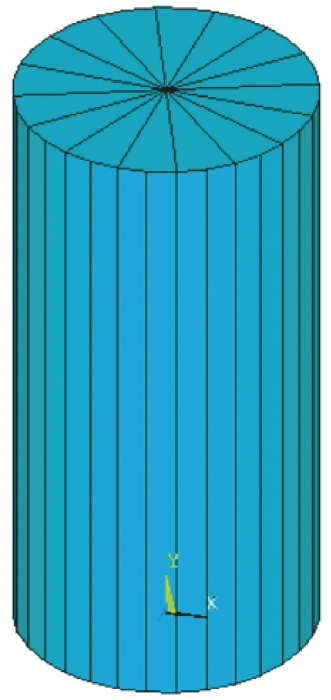

(a)

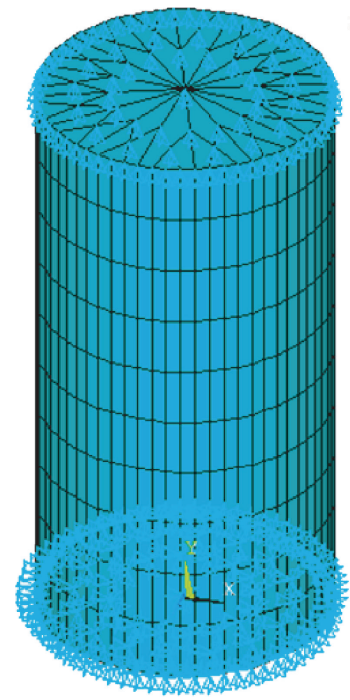

(b)

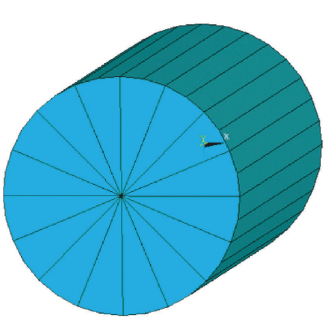

(c)

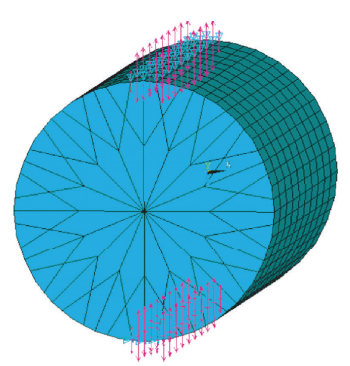

(d)

Figure 5: FE model and boundary condition (BC): ((a) and (b)) compression specimen before meshing and after meshing with BC, respectively, ((c) and (d)) splitting tensile specimen before meshing and after meshing with BC, respectively.

TABLE 2: FE governing parameters.

\begin{tabular}{lcccc}
\hline FE governing parameters & Brick concrete & Stone concrete & Brick SFRC & Stone SFRC \\
\hline Modulus of elasticity $(\mathrm{psi})$ & $24,50,000$ & $25,22,500$ & $25,50,000$ & $28,36,667$ \\
Stress-strain relationship & From experiment & From experiment & From experiment & From experiment \\
Poisson's ratio & 0.35 & 0.25 & 0.37 & 0.30 \\
Shear transfer coefficient for open crack & 0.3 & 0.3 & 0.3 & 0.3 \\
Shear transfer coefficient for closed crack & 0.6 & 0.6 & 1.0 & 1.0 \\
Tensile strength (psi) & 648 & 448 & 944 & 1104 \\
\hline
\end{tabular}

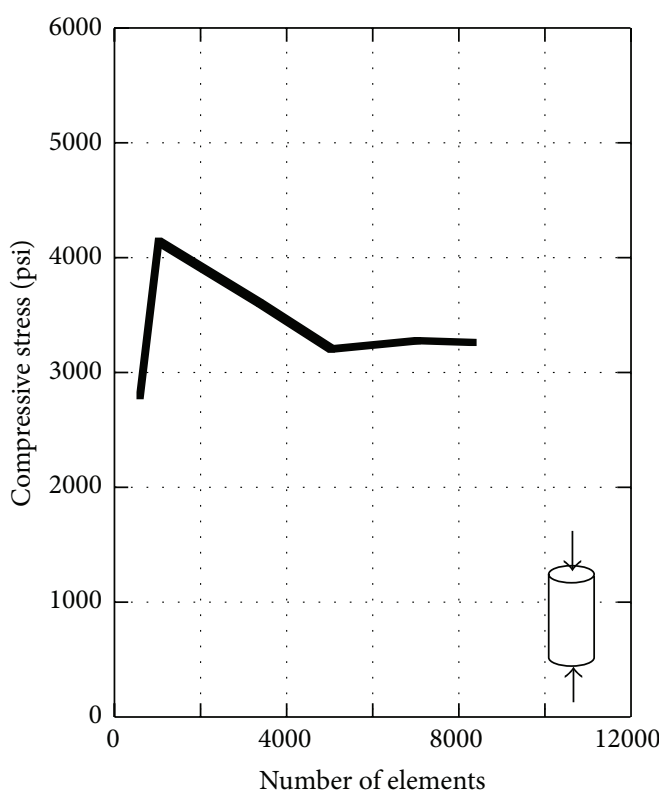

(a)

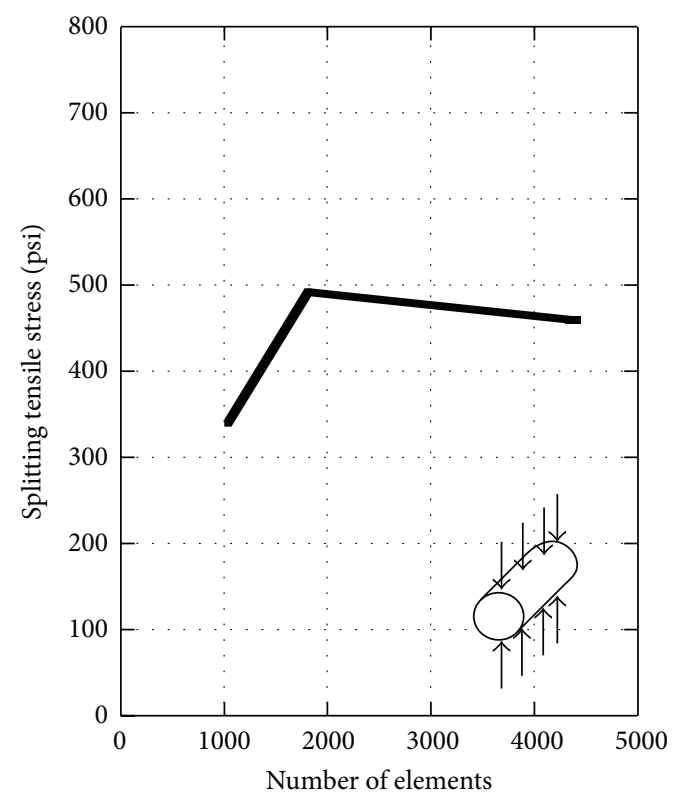

(b)

FIGURE 6: ((a) and (b)) Mesh analysis for compression and split tension cylinder FE models. 

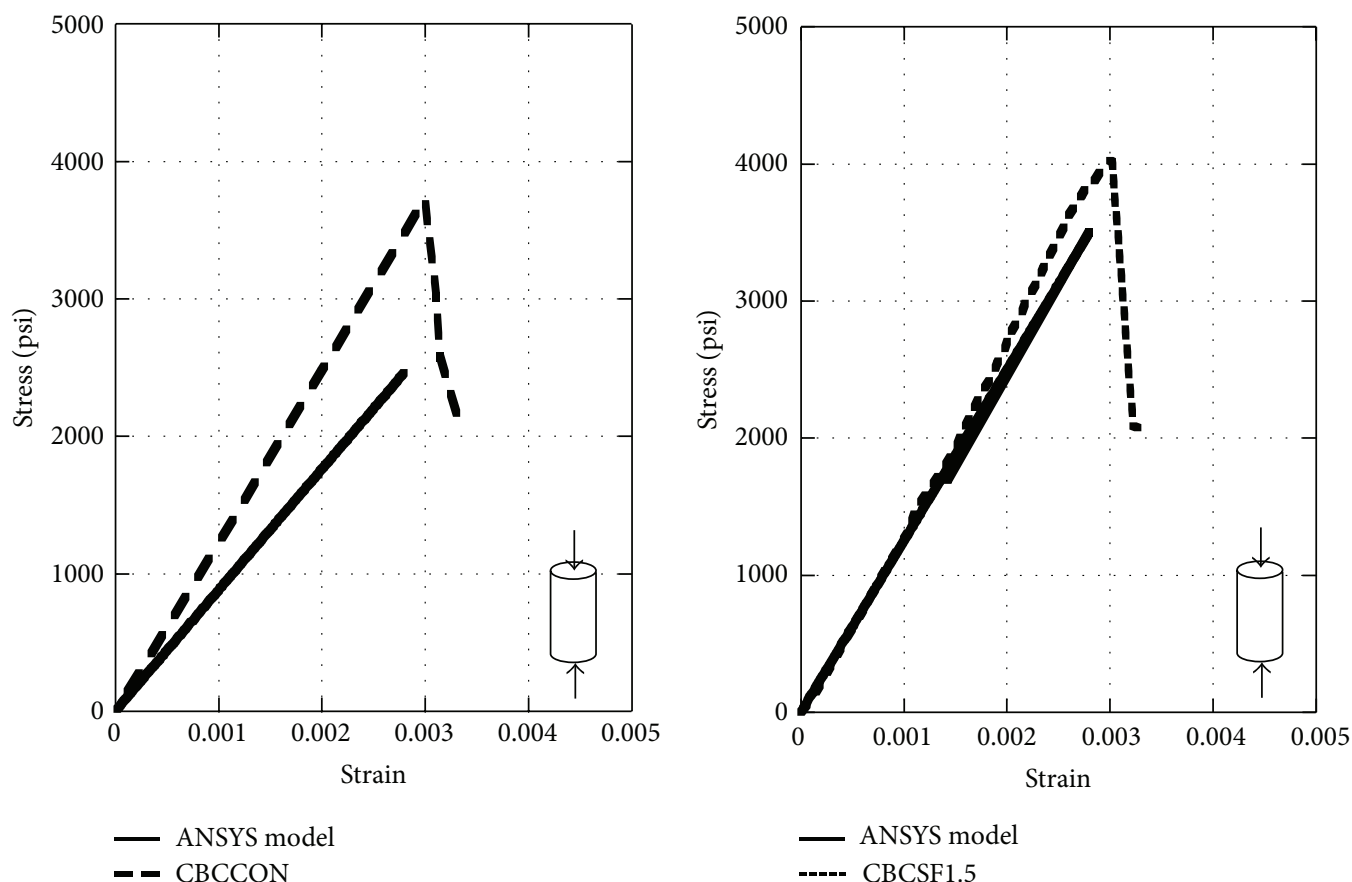

(a)
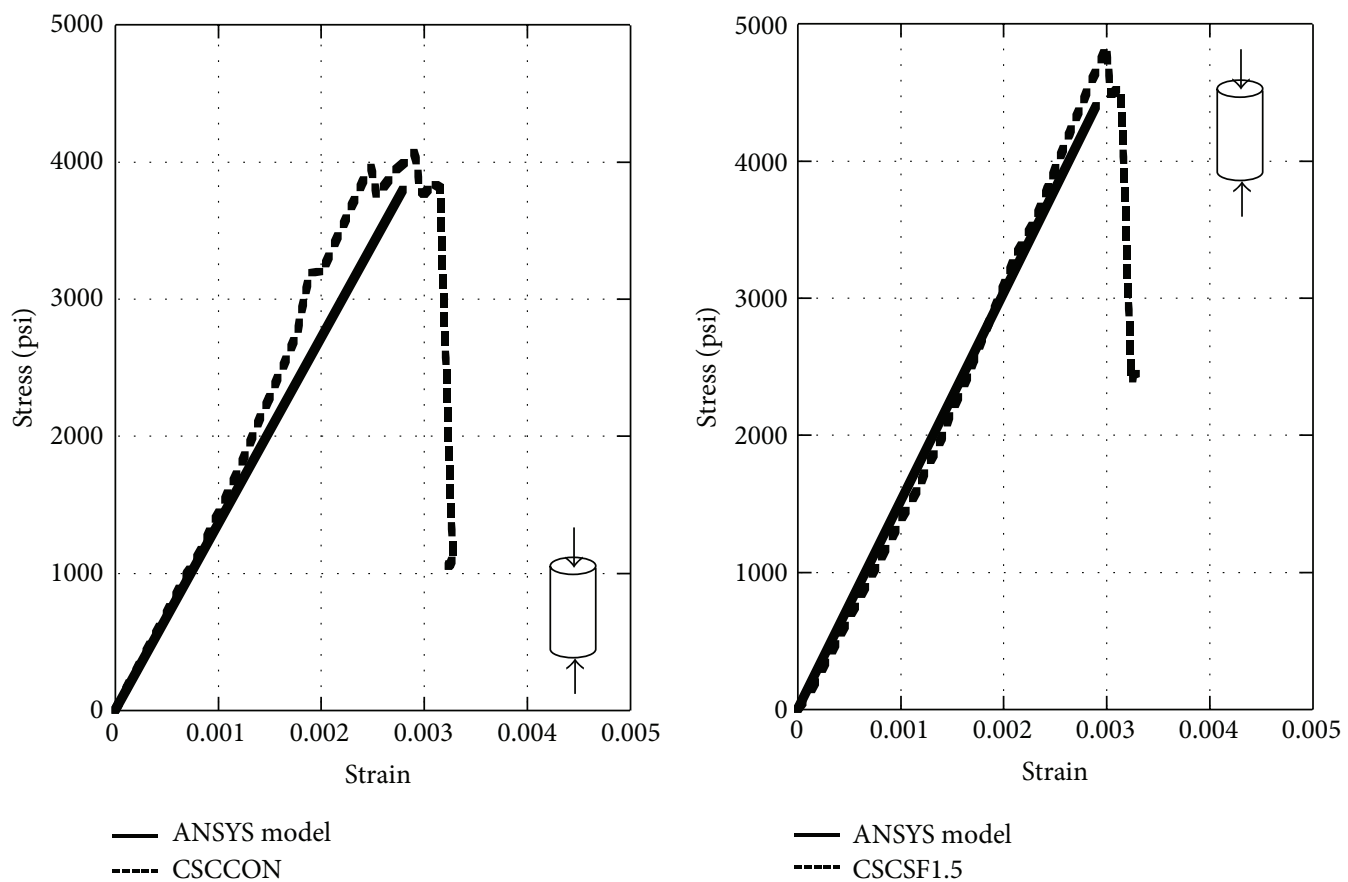

(c)

(d)

FIGURE 7: Evaluation of compressive stress-strain behavior from experimental tests and FE analyses: (a) brick concrete, (b) brick SFRC, (c) stone concrete, and (d) stone SFRC.

analyses are done for compression and splitting cylinder specimens. The number of elements selected for compression cylinder and split cylinder test is 5500 and 4000 elements, respectively. Figure 6 represents the mesh analysis results.
3.6. Evaluation of FE Outcomes. Figure 7 shows the evaluation of compressive stress-strain behavior from experimental tests and FE analyses and Figure 8 represents the evaluation of tensile stress-strain behaviors. The FE outcomes hold good 

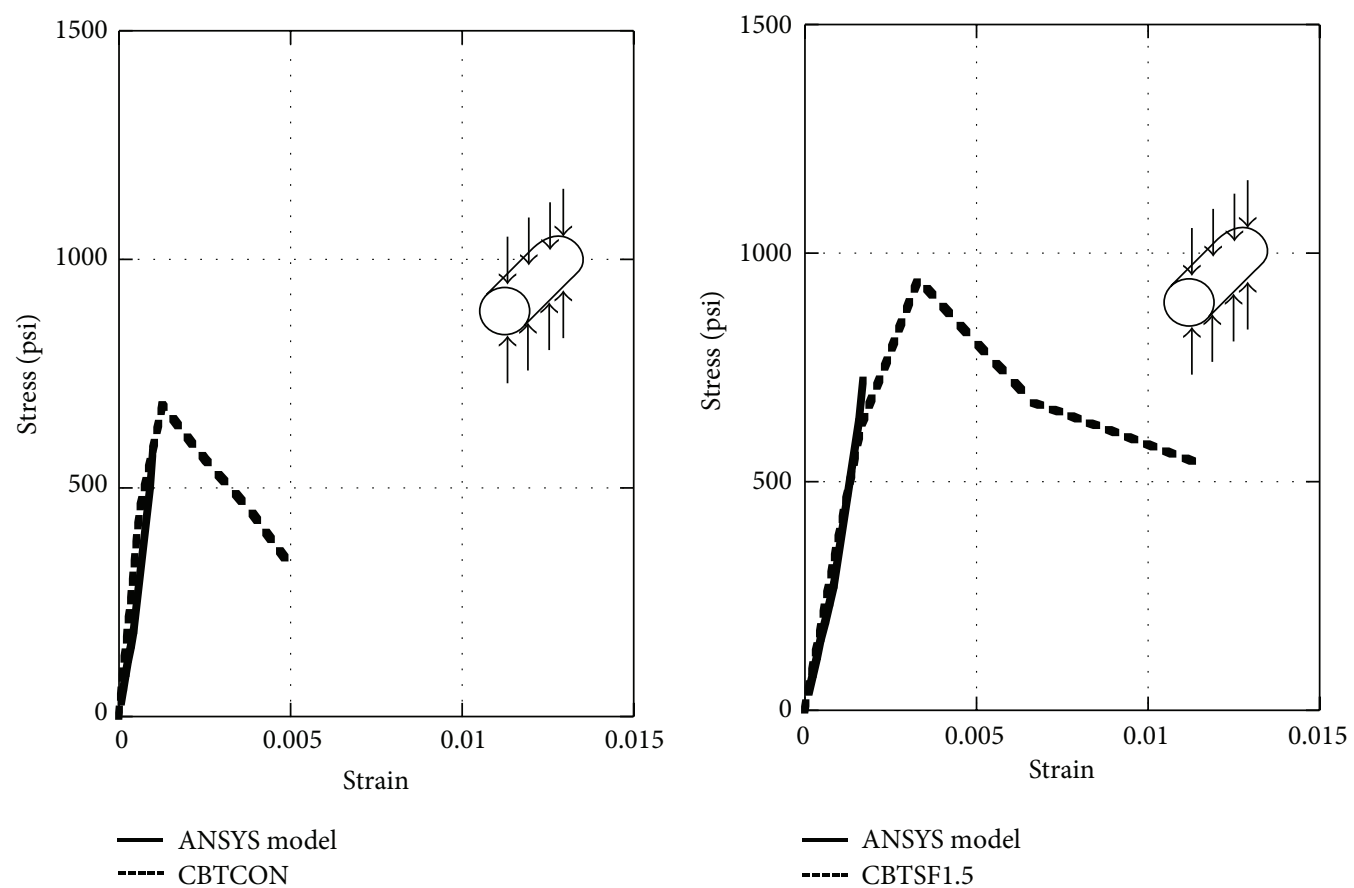

(a)

(b)
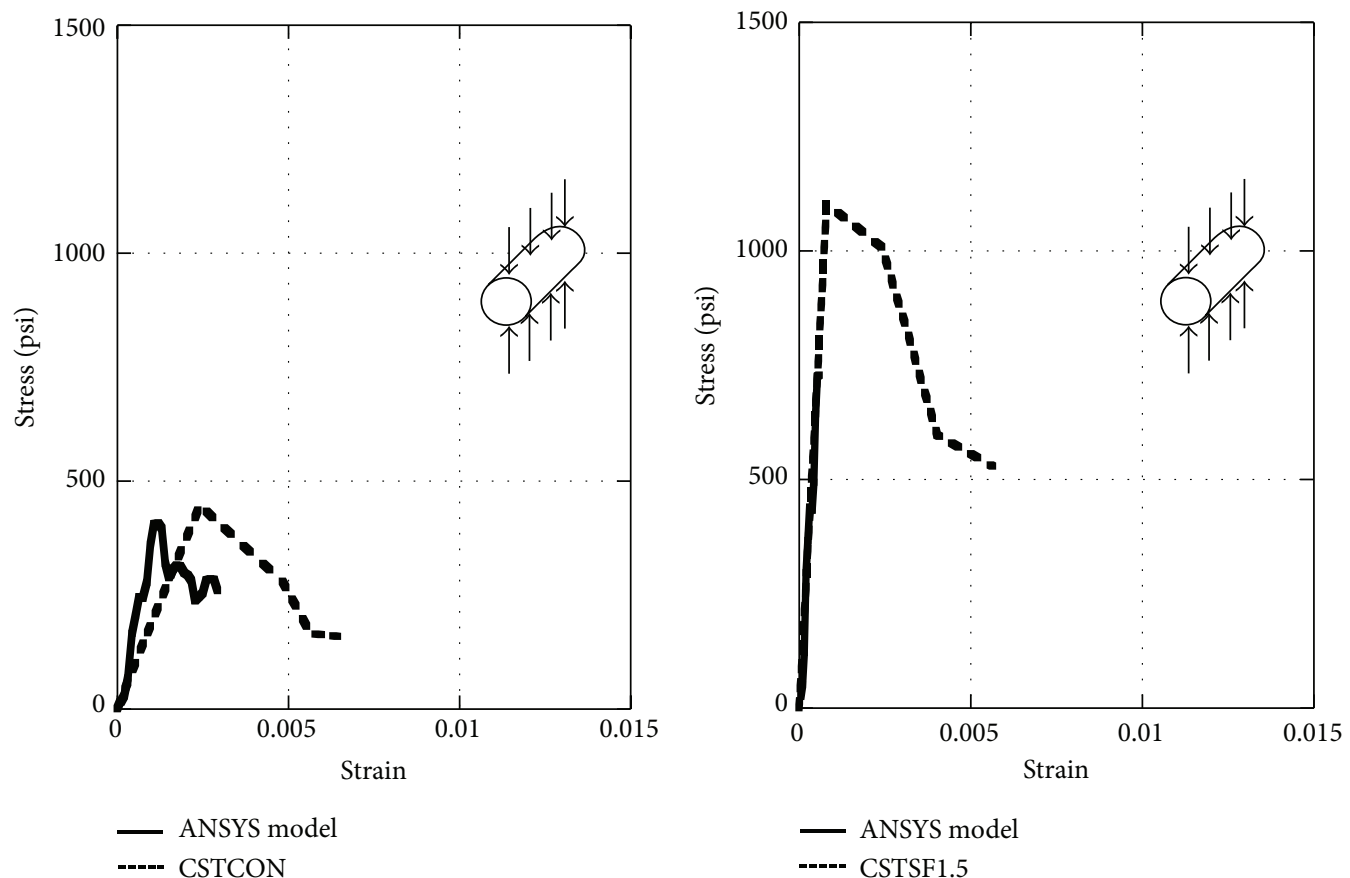

(c)

(d)

FIGURE 8: Evaluation of tensile stress-strain behavior from experimental tests and FE analyses: (a) brick concrete, (b) brick SFRC, (c) stone concrete, and (d) stone SFRC.

agreement with experimental results. The FE models created on the ANSYS 10.0 platform are found capable of estimating the compressive and tensile behavior of plain concrete and the enhanced stress field for SFRC made of brick and stone aggregates. It is also evident that the FE models show slightly conservative results compared to experimental investigations, which ensures adequate factor of safety. Moreover, the FE models show linear behavior, indicating that the results are within the proportional limit and enabling easy estimation of the working stress limit. 


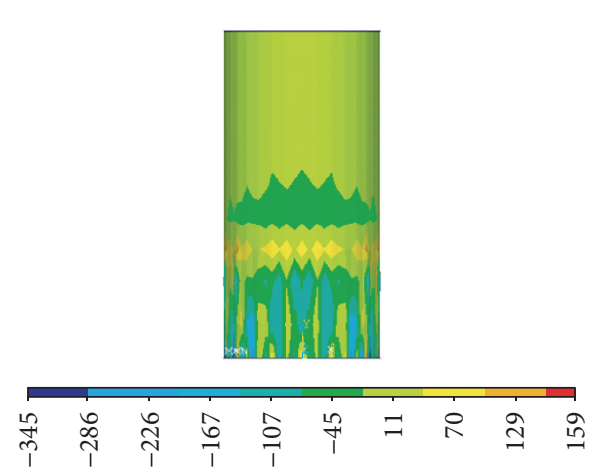

(a)

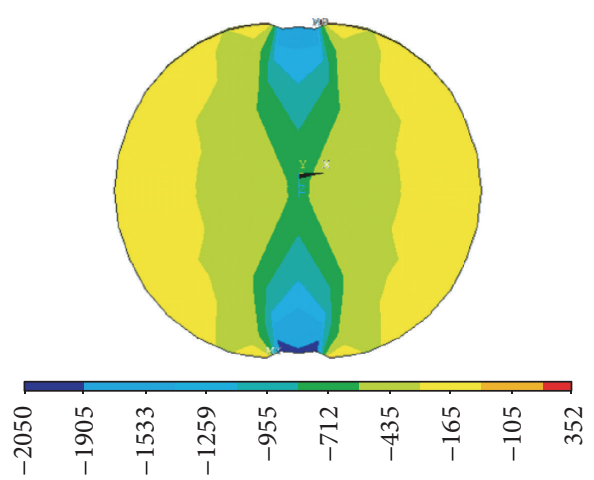

(d)

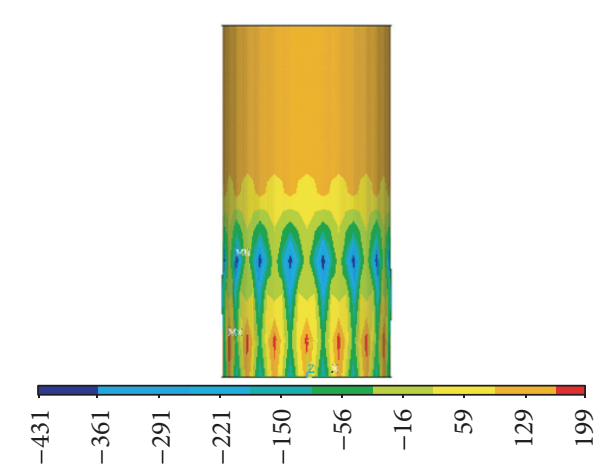

(b)

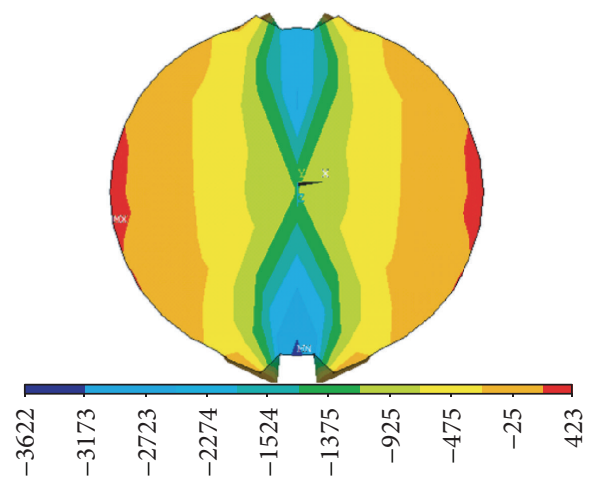

(e)

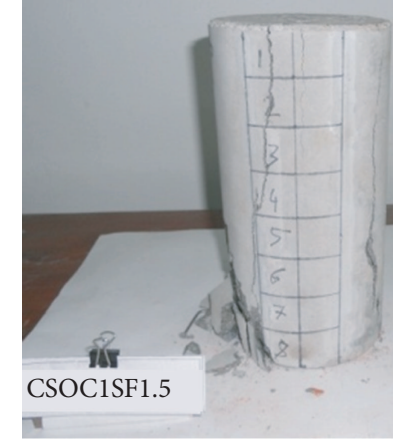

(c)

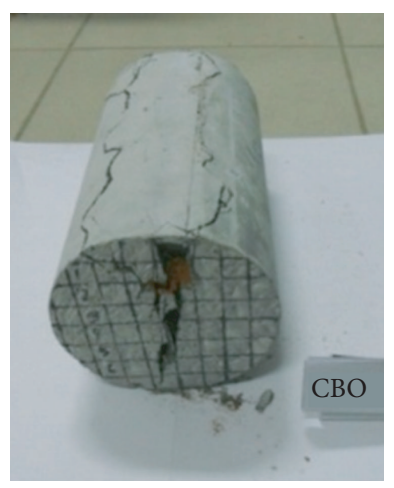

(f)

Figure 9: Typical stress contour of FE models, ((a), (b)) $Y$ direction stress contour of control and SFRC specimen for compression test, respectively, (c) failure occurring at same location during test, ((d) and (e)) $Z$ direction stress contour of control and SFRC specimen for compression test, respectively, and (f) failure pattern during test.

3.7. Evaluation of Stress Contours. The stress contours of the FE models are shown in Figure 9. The stress concentration is found higher at the bottom in the compression specimen, conforming to the experimental observation of cracks found in similar locations. In case of splitting cylinder specimens, stress concentration is in the direction of line loading, which agrees with cracks developed in the same direction experimentally. The stress contours are similar in plain concrete and SFRC but the SFRC showed higher load carrying capacity before failure. In addition, the crack locations are almost the same location of high stress zone in FE models.

3.8. Evaluation of Failure Patterns. During the compressive strength test of control specimen, spalling effect is observed at the lower end while whole cylinder is split during split tension test which indicated the brittleness of the specimens. After using steel fiber of $1.5 \%$, the failure pattern has changed from brittle to ductile while fibers are efficient in arresting the crack propagation. Lower disintegration of concrete is observed in SFRC specimens having higher capacity. Figures 10 and 11 depict the images of failure patterns during experimental test and FE analyses.

\section{Conclusion}

Based on the experimental investigation and FE analysis, the following conclusion can be made:

(1) The compressive strength of brick and stone SFRC is found to be enhanced by up to $17 \%$ compared to respective plain concrete specimens. In case of tensile strength, the brick concrete showed higher tensile capacity compared to stone concrete. But tensile capacity enhancement is found higher in stone SFRC. The enhancement in brick SFRC and stone SFRC is about $46 \%$ and $146 \%$, respectively.

(2) The FE outcomes hold good agreement with experimental results. The FE models created on the ANSYS 10.0 platform are found capable of estimating the compressive and tensile behavior of plain concrete and the enhanced stress field for SFRC made of brick and stone aggregates. It is also clear that the FE models show slightly conservative results compared to experimental investigations, which ensures 


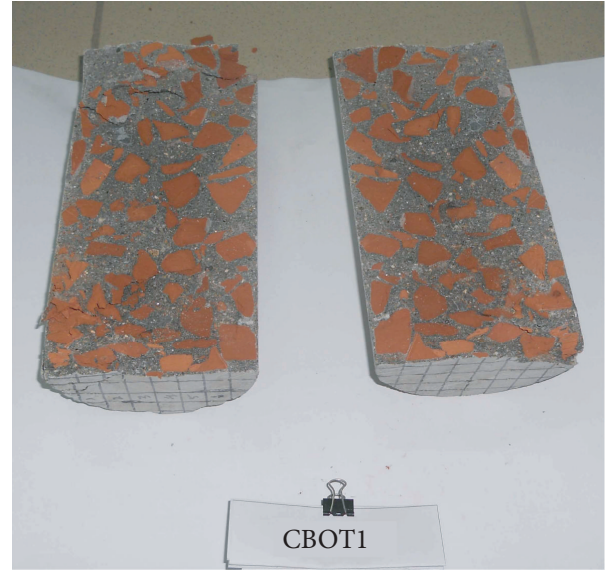

(a)

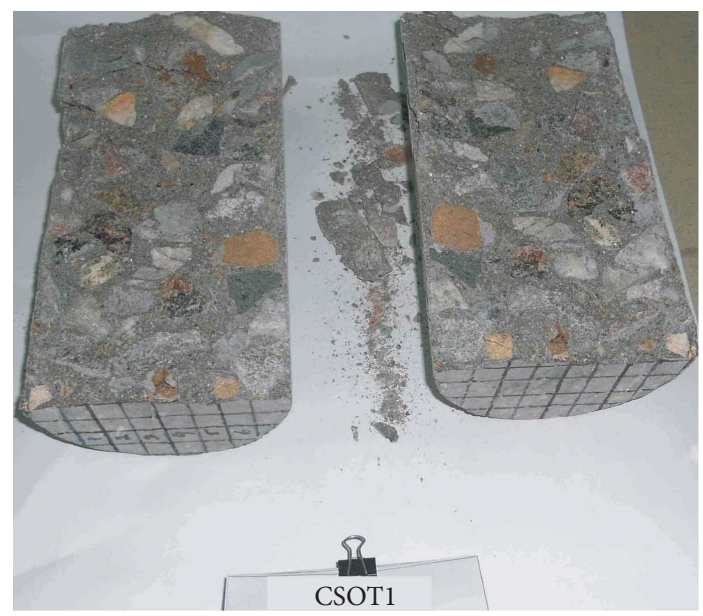

(c)

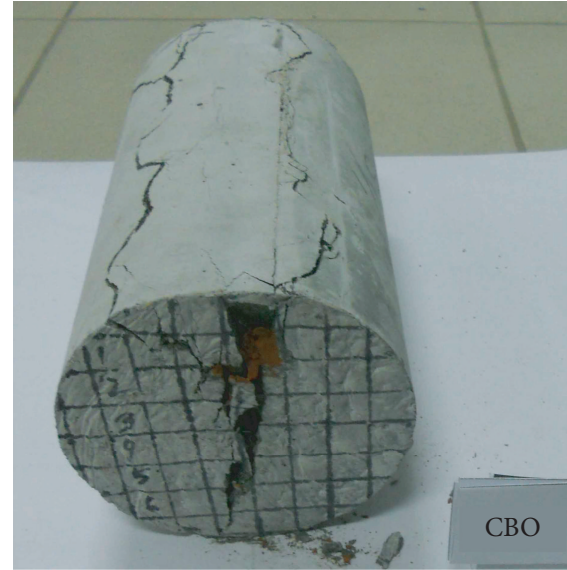

(b)

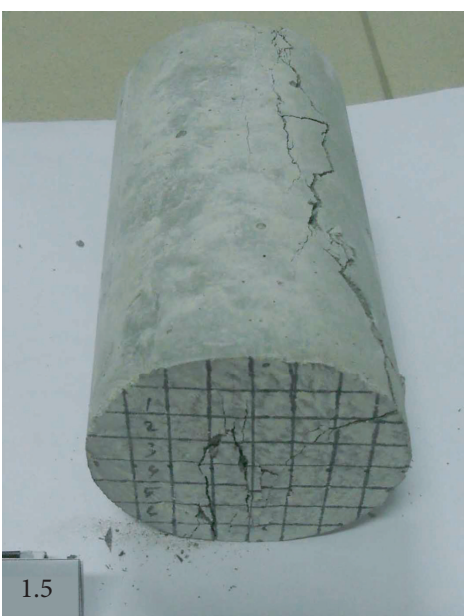

(d)

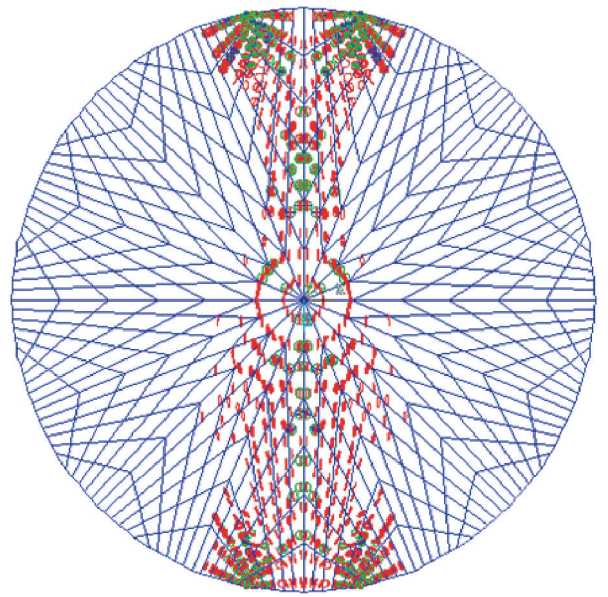

(e)

FIGURE 10: Failure patterns of splitting tensile specimens, (a) brick concrete, (b) brick SFRC, (c) stone concrete, (d) stone SFRC, and (e) failure pattern of FE model.

adequate factor of safety. The FE models also show linear behavior which indicates that the results are within the proportional limit and also the working stress limit may also be estimated easily.
(3) The stress contours of compressive and tensile specimens showed higher concentration where the cracks were found experimentally, which ensures the same behavior of the FE model as experimental specimens. 


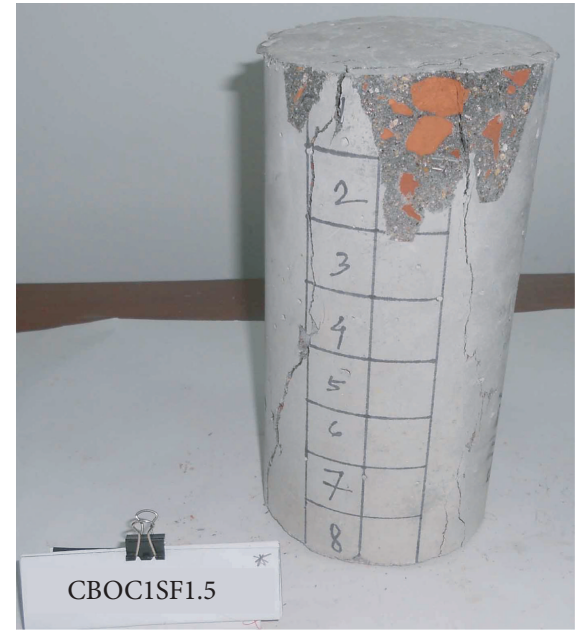

(a)

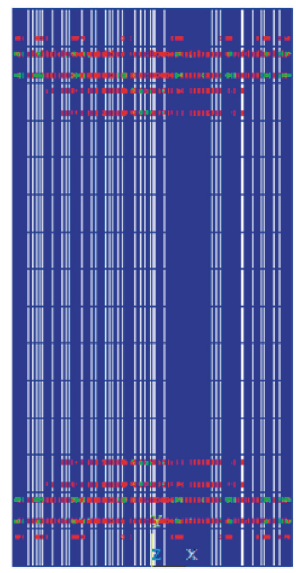

(c)

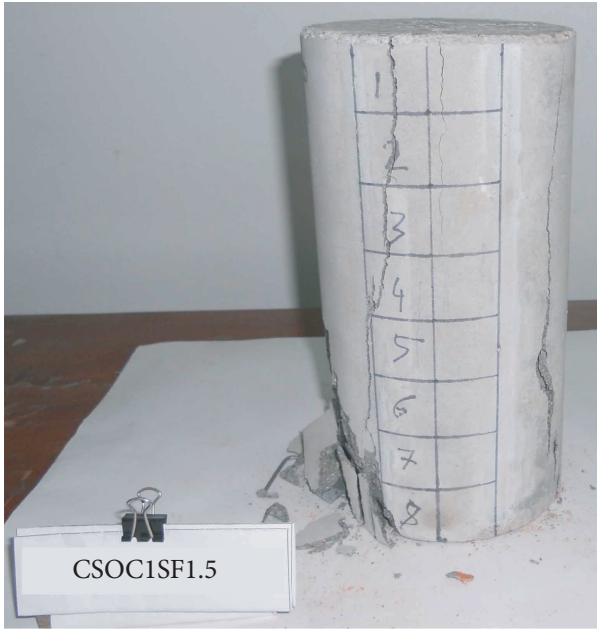

(b)

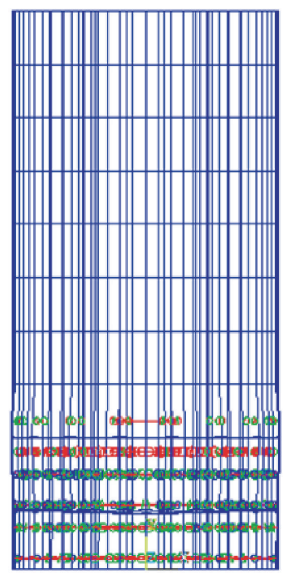

(d)

FIGURE 11: Failure patterns of compression specimens, (a) brick SFRC, (b) brick SFRC, and ((c) and (d)) failure pattern of FE models.

(4) Crack pattern and location of FE models and experimental specimens are brilliantly matched and thus also validate the FE modeling and analyses.

(5) In the absence of a reliable model for predicting the compressive strength and tensile strength of SFRC with the easily available fibers in context of Bangladesh, the current research successfully investigated the compressive and splitting tensile capacity enhancements and stress fields of the SFRC experimentally and within numerical viewpoint. It is indeed a worthwhile attempt to introduce this new engineering material in the Bangladesh construction industry with reliable experimental results and FE modeling.

\section{Competing Interests}

The authors declare that they have no competing interests.

\section{References}

[1] B. Graybeal and M. Davis, "Cylinder or cube: strength testing of 80 to $200 \mathrm{MPa}$ (11.6 to $29 \mathrm{ksi}$ ) ultra-high-performance fiberreinforced concrete," ACI Materials Journal, vol. 105, no. 6, pp. 603-609, 2008.

[2] H. Aoude, W. D. Cook, and D. Mitchell, "Behavior of columns constructed with fibers and self-consolidating concrete," $A C I$ Structural Journal, vol. 106, no. 3, pp. 349-357, 2009.

[3] Z. L. Wang, Z. M. Shi, and J. G. Wang, "On the strength and toughness properties of SFRC under static-dynamic compression," Composites Part B: Engineering, vol. 42, no. 5, pp. 12851290, 2011.

[4] K. Marar, Ö. Eren, and İ. Yitmena, "Compression specific toughness of normal strength steel fiber reinforced concrete (NSSFRC) and high strength steel fiber reinforced concrete (HSSFRC)," Materials Research, vol. 14, no. 2, pp. 239-247, 2011.

[5] ACI Committee 544, "Design considerations for steel fiber reinforced concrete," Tech. Rep. ACI 544.4R-88, American Concrete Institute, 1999. 
[6] T. C. Yet, R. Hamid, and M. Kasmuri, "Dynamic stress-strain behaviour of steel fiber reinforced high-performance concrete with fly ash," Advances in Civil Engineering, vol. 2012, Article ID 907431, 6 pages, 2012.

[7] ASTM, "Compressive strength of cylindrical concrete specimens," ASTM C 39/C 39M-05, American Society for Testing and Materials (ASTM) Committee C09, 2006.

[8] ASTM C 496/C 496M-04, Splitting Tensile Strength of Cylindrical Concrete Specimens, vol. C09, American Society for Testing and Materials (ASTM) Committee, 2006.

[9] M. M. Islam, Interaction diagrams of square concrete columns confined with fiber reinforced polymer wraps [M. S. thesis Engineering], Bangladesh University of Engineering and Technology, Dhaka, Bangladesh, 2011.

[10] M. K. Uddin, A. Z. Mustafiz, M. A. Chowdhury, and P. Mondal, Investigation of the flexural capacity of beams made of steel fiber reinforced concrete (SFRC) [B.Sc. engineering thesis], Department of Civil Engineering, Ahsanullah University of Science and Technology, Dhaka, Bangladesh, 2013.

[11] J. F. Dola, M. R. Islam, M. S. Khatun, and M. Hussan, Investigation of the shear capacity of beams made of steel fiber reinforced concrete (SFRC) [B.Sc. engineering thesis], Department of Civil Engineering, Ahsanullah University of Science and Technology, Dhaka, Bangladesh, 2013.

[12] ASTM A 820/A 820M-06, Standard Specification for Steel Fibers for Fiber-Reinforced Concrete, vol. A01, American Society for Testing and Materials (ASTM) Committee, 2006.

[13] K. J. Willam and E. D. Warnke, "Constitutive model for the triaxial behavior of concrete," in Proceedings of the International Association for Bridge and Structural Engineering, vol. 19, pp. 130, ISMES, Bergamo, Italy, 1975.

[14] D. I. Kachlakev, T. Miller, S. Yim, K. Chansawat, and T. Potisuk, Finite Element Modeling of Reinforced Concrete Structures Strengthened with FRP Laminates, California Polytechnic State University, San Luis Obispo, Calif, USA; Oregon Department of Transportation, Oregon State University, Corvallis, Ore, USA, 2001. 


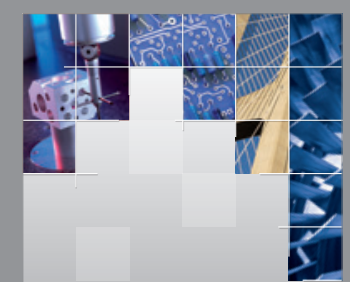

\section{Enfincering}
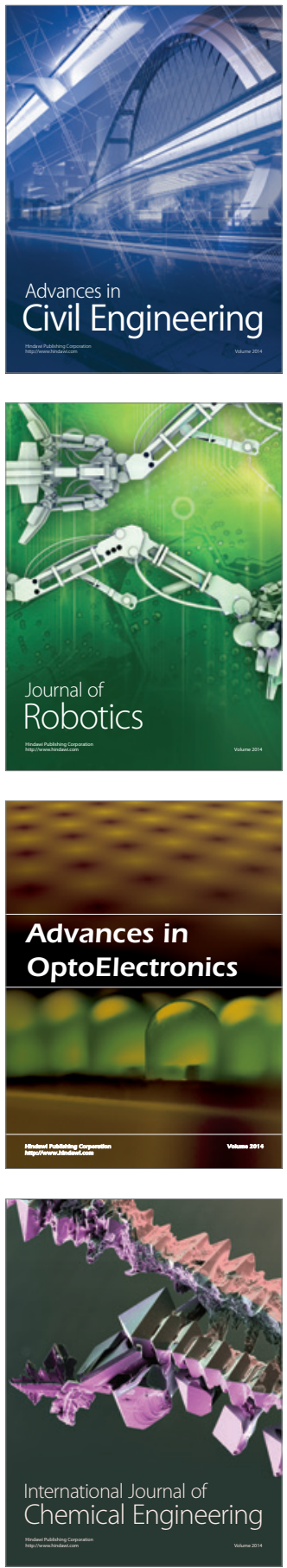

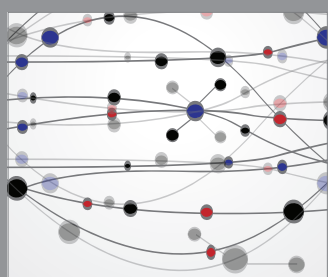

The Scientific World Journal

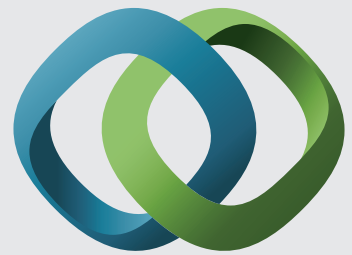

\section{Hindawi}

Submit your manuscripts at

http://www.hindawi.com
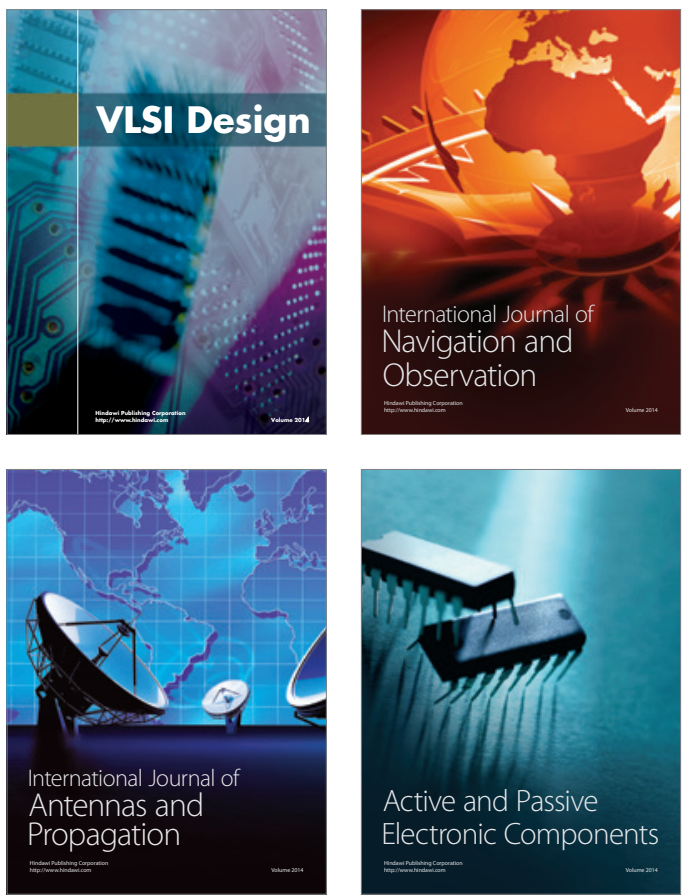
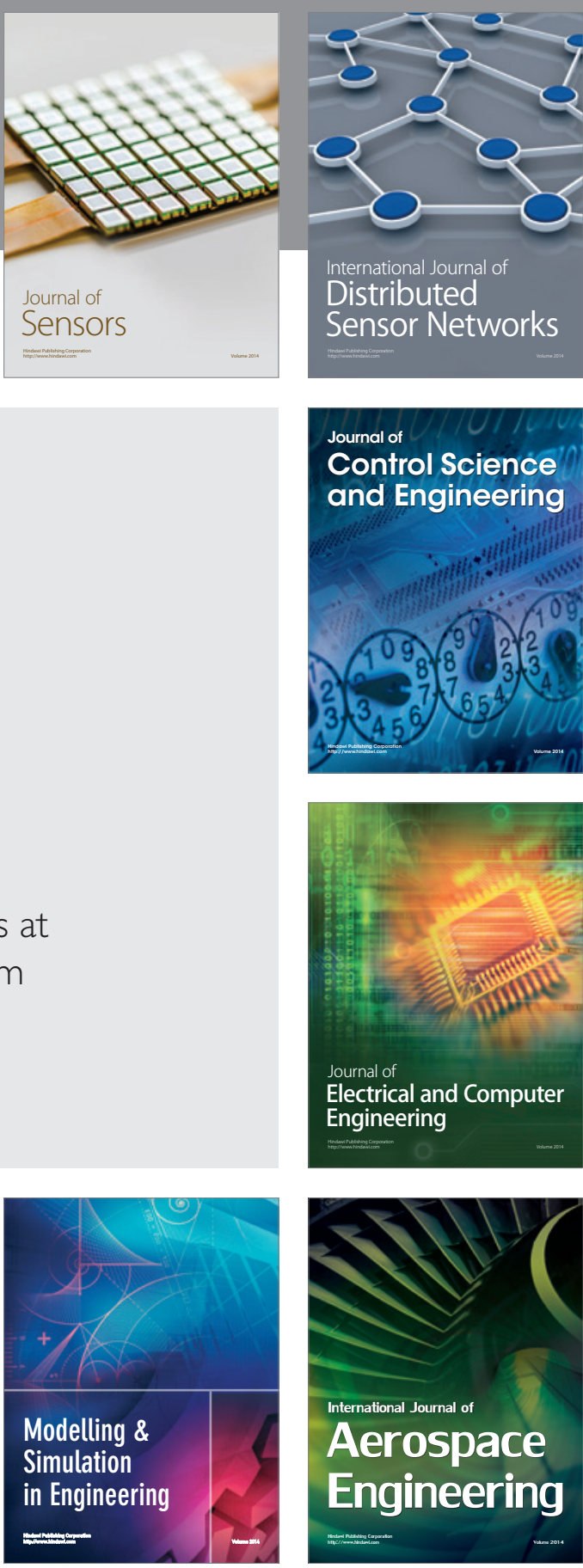

International Journal of

Distributed

Sensor Networks

Journal of

Control Science

and Engineering
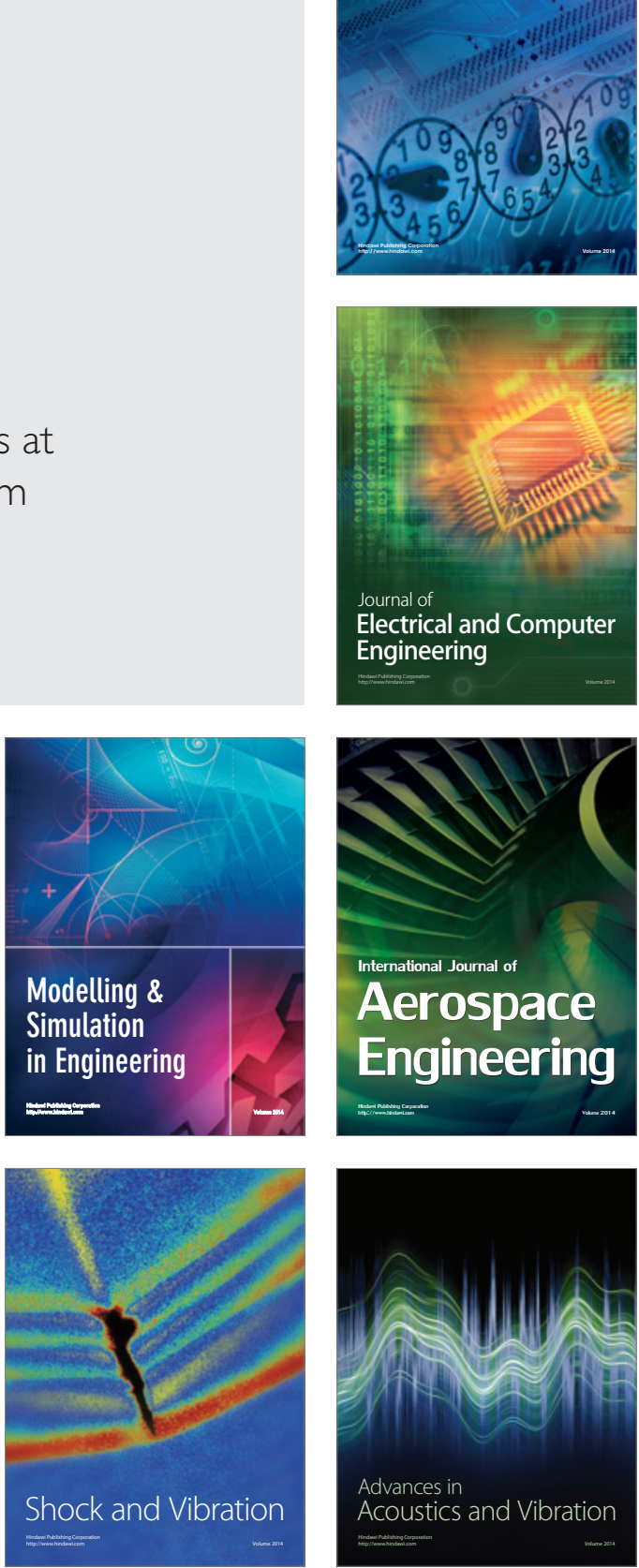